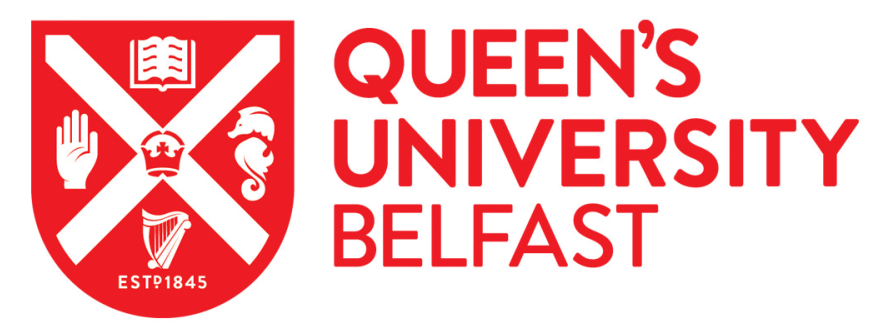

\title{
Comment on "A tensorial based progressive damage model for fibre reinforced polymers"
}

Falzon, B. G., Liu, H., \& Tan, W. (2017). Comment on "A tensorial based progressive damage model for fibre reinforced polymers". Composite Structures, 176, 877-882. https://doi.org/10.1016/j.compstruct.2017.06.011

Published in:

Composite Structures

Document Version:

Peer reviewed version

Queen's University Belfast - Research Portal:

Link to publication record in Queen's University Belfast Research Portal

Publisher rights

(C) 2017 Elsevier Ltd This manuscript is distributed under a Creative Commons Attribution-NonCommercial-NoDerivs License

(https://creativecommons.org/licenses/by-nc-nd/4.0/), which permits distribution and reproduction for non-commercial purposes, provided the author and source are cited.

\section{General rights}

Copyright for the publications made accessible via the Queen's University Belfast Research Portal is retained by the author(s) and / or other copyright owners and it is a condition of accessing these publications that users recognise and abide by the legal requirements associated with these rights.

Take down policy

The Research Portal is Queen's institutional repository that provides access to Queen's research output. Every effort has been made to ensure that content in the Research Portal does not infringe any person's rights, or applicable UK laws. If you discover content in the Research Portal that you believe breaches copyright or violates any law, please contact openaccess@qub.ac.uk. 


\section{Accepted Manuscript}

Short Communication

Comment on " 'A tensorial based progressive damage model for fiber reinforced polymers"

Brian G. Falzon, Haibao Liu, Wei Tan

PII:

S0263-8223(17)31730-0

DOI: http://dx.doi.org/10.1016/j.compstruct.2017.06.011

Reference: COST 8598

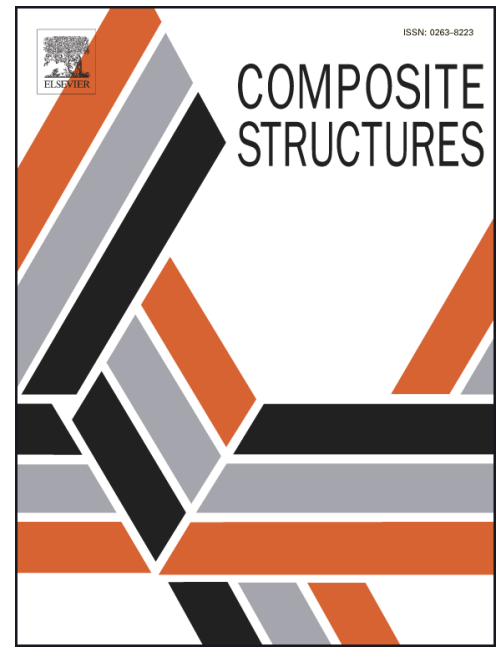

To appear in:

Composite Structures

Received Date:

31 May 2017

Accepted Date:

6 June 2017

Please cite this article as: Falzon, B.G., Liu, H., Tan, W., Comment on ' 'A tensorial based progressive damage model for fiber reinforced polymers", Composite Structures (2017), doi: http://dx.doi.org/10.1016/j.compstruct. 2017.06.011

This is a PDF file of an unedited manuscript that has been accepted for publication. As a service to our customers we are providing this early version of the manuscript. The manuscript will undergo copyediting, typesetting, and review of the resulting proof before it is published in its final form. Please note that during the production process errors may be discovered which could affect the content, and all legal disclaimers that apply to the journal pertain. 


\section{Comment on "A tensorial based progressive damage model for fiber reinforced polymers"}

Brian G. Falzona ${ }^{*}$, Haibao Liua, Wei Tan ${ }^{b}$

a School of Mechanical and Aerospace Engineering, Queen's University Belfast, Ashby Building, Belfast BT9 $5 A H, U K$

${ }^{b}$ Engineering Department, University of Cambridge, Trumpington Street, Cambridge CB2 1PZ, UK

* Corresponding author: b.falzon@qub.ac.uk (Brian G. Falzon)

Tel: +44 (0)2890975640

\section{Abstract}

This communication is in response to unsubstantiated claims, arising from misinterpretations and misrepresentations, made by Bogenfield and Kreikemeier in their recent paper, "A tensorial based progressive damage model for fiber reinforced polymers"[1], on a damage model developed by Falzon et al. [2]. While details of this model have been extensively reported in a number of publications (e.g. [2-4]), and validated through comprehensive experimental programmes, this brief paper provides additional information on the damage model's formulation for the purpose of clarification and rebutting the conclusions in [1]. The test cases reported in [1], to demonstrate the apparent shortcomings of the damage model in [2], are repeated here to show that the alleged shortcomings are non-existent and consequently provide further support for the robustness and predictive capability of Falzon's progressive damage model. 
Keywords: Continuum damage mechanics, Damage model, Finite element simulation.

\section{Introduction}

This communication is primarily concerned with highlighting fundamental misunderstandings and misrepresentations of the model presented in [2], by the authors in [1]. It is not concerned with assessing the merits, or otherwise, of the damage model presented by Bogenfield and Kreikemeier [1] although it has long been established that an eighth order damage tensor is not required to represent the most general form of damage arising from the concept of stiffness degradation and strain equivalence [5]. It is also worth pointing out that the basic definition of the constitutive damage law for intralaminar tensile damage reported in Fig. 2 in [1] contains two basic inaccuracies. The first concerns the area under the bilinear constitutive curve which Bogenfield and Kreikemeier refer to as the energy release rate $(G)$ but which is actually the strain energy density, hence the requirement for the use of a characteristic length. The second concerns the label attached to the reduced slope which is given as a function of the stress and damage parameter but which should be a function of the pristine elastic modulus and damage parameter.

\section{Damage model}

\subsection{Basic principles}

Continuum damage mechanics [6] is based on the concept that before the onset of macroscopic fracture (i.e. net section failure in the Representative Volume Element (RVE), under uniaxial loading, shown in Fig. 1), microscopic cracks and voids form within the material under loading [7]. With reference to Fig. 1 (left), the damage in the cross-sectional area, $A$, under damage-inducing load, $F$, 
leads to a reduction in the effective load bearing area, represented by a fictitious state of the material shown in Fig. 1 (right) where $\tilde{A}$ represents the difference in the cross-sectional area, $A$, of the original (damaged) specimen and the area representing the microscopic damage. The reduction of the load bearing area (from $A$ to $\tilde{A}$ ) may be quantified by a damage parameter, $d$, as shown in Eq. (1),

$$
(1-d)=\frac{\tilde{A}}{A}
$$

This reduction in load bearing area leads to a corresponding reduction in transmitted stress, $\sigma$, in the damaged material. Combining with the damage parameter defined in Eq. (1), the stress is given by Eq. (2) which relates the transmitted stress to an 'effective' stress, $\tilde{\sigma}$, in the 'fictitious' undamaged configuration,

$$
\sigma=(1-d) \tilde{\sigma}
$$

The principle of strain equivalence assumes that the strains in the damaged material, Fig 1. (left), and 'fictitious' material, (Fig. 1, right) are equal, $\varepsilon=\tilde{\varepsilon}$. Using the constitutive relations, $\sigma=E \varepsilon$ and $\tilde{\sigma}=\tilde{E} \tilde{\varepsilon}$, where $E$ is the modulus of the damaged material and $\tilde{E}$ is the modulus of the fictitious (undamaged/pristine) material, it may be easily shown that,

$$
E=(1-d) \tilde{E}
$$




\subsection{Global constitutive law (ply level)}

Fig. 2 shows a representative volume element (RVE) of a composite ply where 1 is the fibre direction and orthogonal directions 2 and 3 are the transverse and through-thickness directions, respectively, which are dominated by matrix properties. By strain equivalence,

$$
\widetilde{\sigma}=C: \varepsilon
$$

where $\boldsymbol{C}$ is the pristine stiffness matrix.

After damage initiation, both the moduli and Poisson ratios are degraded,

$$
\frac{v_{i j, d}}{E_{i i, d}}=\frac{v_{i j}\left(1-d_{i i}\right)}{E_{i i}\left(1-d_{i i}\right)}=\frac{v_{j i}\left(1-d_{j j}\right)}{E_{j j}\left(1-d_{j j}\right)}=\frac{v_{j i, d}}{E_{j j, d}}, i, j=1,2,3 i \neq j .
$$

\subsection{Fibre-dominated damage model}

The deformation of the RVE in the fibre direction is shown in Fig. 3. A strain-based failure initiation criterion, in the fibre-dominated direction, is used in the analysis [8]. It is to be noted that extensive validation $[2,4,9-14]$ has shown that the need for coupling of this failure mode does not lead to significantly improved accuracy. For fibre-dominated damage, the fracture surface is assumed to be perpendicular to the loading direction such that the fracture surface coordinate system is coincident with the material coordinate system (123). In the computational subroutine, a damage tensor for fibre damage, $\boldsymbol{D}_{f i b}$, is defined, along with a stiffness matrix with Poisson degradation only, $\widehat{\boldsymbol{C}}$, 


$$
\begin{gathered}
\boldsymbol{\sigma}_{123}=\boldsymbol{D}_{f i b} \widehat{\boldsymbol{C}}: \boldsymbol{\varepsilon}_{123}=\boldsymbol{D}_{f i b}: \widehat{\boldsymbol{\sigma}}_{123} \\
\boldsymbol{D}_{f i b}=\left[\begin{array}{cccccc}
\left(1-d_{f i b}\right) & 0 & 0 & 0 & 0 & 0 \\
0 & 1 & 0 & 0 & 0 & 0 \\
0 & 0 & 1 & 0 & 0 & 0 \\
0 & 0 & 0 & 1 & 0 & 0 \\
0 & 0 & 0 & 0 & 1 & 0 \\
0 & 0 & 0 & 0 & 0 & 1
\end{array}\right]
\end{gathered}
$$

and $\widehat{\boldsymbol{\sigma}}_{123}$ is a non-physical stress vector, introduced for computational expediency, which is based on the product of $\widehat{\boldsymbol{C}}$ and the strain, $\boldsymbol{\varepsilon}_{123}$.

\subsection{Matrix-dominated damage model}

The matrix-dominated damage model uses Puck's stress-based damage initiation criterion [15]. The orientation of the fracture surface (coordinate system $L N T$ ), defined by the angle, $\theta_{f}$, in Fig. 4 , is determined by the 3D stress state acting on the RVE. This requires $\widehat{\boldsymbol{\sigma}}_{123}$, expressed as a stress tensor, to be rotated onto the fracture plane using the standard rotation tensor $\boldsymbol{T}\left(\theta_{f}\right)$,

$$
\widehat{\boldsymbol{\sigma}}_{L N T}=\boldsymbol{T}\left(\theta_{f}\right) \widehat{\boldsymbol{\sigma}}_{123} \boldsymbol{T}^{\boldsymbol{T}}\left(\theta_{f}\right)
$$

The degraded stress vector on the fracture plane, $\boldsymbol{\sigma}_{L N T}$, may then be expressed as,

$$
\boldsymbol{\sigma}_{L N T}=\boldsymbol{D}_{m a t}: \widehat{\boldsymbol{\sigma}}_{L N T}
$$

where $\boldsymbol{D}_{\text {mat }}$ is a matrix damage tensor in which a damage parameter, $d_{\text {mat }}$, is derived from a constitutive bilinear law $[10,16,17]$, 


$$
\boldsymbol{D}_{\text {mat }}=\left[\begin{array}{cccccc}
1 & 0 & 0 & 0 & 0 & 0 \\
0 & \left(1-d_{m a t} \boldsymbol{\delta}_{i j}\right) & 0 & 0 & 0 & 0 \\
0 & 0 & 1 & 0 & 0 & 0 \\
0 & 0 & 0 & \left(1-d_{m a t} \boldsymbol{\delta}_{i j}\right) & 0 & 0 \\
0 & 0 & 0 & 0 & \left(1-d_{m a t} \boldsymbol{\delta}_{i j}\right) & 0 \\
0 & 0 & 0 & 0 & 0 & 1
\end{array}\right]
$$

where $\boldsymbol{\delta}_{i j}$ is the Kronecker delta,

$$
\begin{aligned}
& \boldsymbol{\delta}_{i j}=1 \quad \text { if } i \neq j \\
& \boldsymbol{\delta}_{i j}=0 \quad \text { if } i=j \cap \tilde{\sigma}_{N N}<0 .
\end{aligned} \quad(i, j=L, N, T)
$$

and

$$
d_{m a t}\left(\varepsilon_{r}\right)=\frac{\varepsilon_{r}^{F}-\varepsilon_{r, i n}^{O}}{\varepsilon_{r}^{F}-\varepsilon_{r}^{O}}\left(\frac{\varepsilon_{r}^{O}-\varepsilon_{r}}{\varepsilon_{r}-\varepsilon_{r, i n}^{O}}\right)
$$

where $\varepsilon_{r}$ is the $l^{2}$-norm of the strain vector $\left[\varepsilon_{N N}, \varepsilon_{L N}, \varepsilon_{N T}\right]^{\top}$ acting on the fracture plane. $\varepsilon_{r}^{O}$ and $\varepsilon_{r}^{F}$ are the $l^{2}$-norms of the damage initiation and final failure strains, respectively. $\varepsilon_{r, i n}^{O}$ is the $l^{2}$-norm of the inelastic strain vector at damage initiation.

The degraded stress tensor on the fracture plane, $\boldsymbol{\sigma}_{L N T}$, is subsequently rotated back to the material coordinate system,

$$
\boldsymbol{\sigma}_{123}=\boldsymbol{T}\left(-\theta_{f}\right) \boldsymbol{\sigma}_{L N T} \boldsymbol{T}^{T}\left(-\theta_{f}\right)
$$




\subsection{Full stress tensor for damaged RVE}

Since the matrix fracture plane is always rotated around the fibre direction, the fibre and matrix damage tensors may be combined in the LNT coordinate system,

$$
\boldsymbol{\sigma}_{L N T}=\boldsymbol{D}_{l}: \widehat{\boldsymbol{\sigma}}_{L N T}
$$

where

$$
\boldsymbol{D}_{l}=\left[\begin{array}{cccccc}
\left(1-d_{f i b}\right) & 0 & 0 & 0 & 0 & 0 \\
0 & \left(1-d_{m a t} \boldsymbol{\delta}_{i j}\right) & 0 & 0 & 0 & 0 \\
0 & 0 & 1 & 0 & 0 & 0 \\
0 & 0 & 0 & \left(1-d_{m a t} \boldsymbol{\delta}_{i j}\right) & 0 & 0 \\
0 & 0 & 0 & 0 & \left(1-d_{m a t} \boldsymbol{\delta}_{i j}\right) & 0 \\
0 & 0 & 0 & 0 & 0 & 1
\end{array}\right]
$$

The resulting global stress tensor $\left(\boldsymbol{\sigma}_{123}\right)$ is obtained by rotating the degraded stress tensor $\left(\boldsymbol{\sigma}_{L N T}\right)$ back to the material coordinate system,

$$
\boldsymbol{\sigma}_{123}=\boldsymbol{T}\left(-\theta_{f}\right) \boldsymbol{\sigma}_{L N T} \boldsymbol{T}^{T}\left(-\theta_{f}\right)
$$

where

$$
\begin{gathered}
\sigma_{11}=\left(1-d_{f i b}\right) \sigma_{L L} \\
\sigma_{22}=\left(1-d_{m a t} \boldsymbol{\delta}_{i j}\right) \sigma_{N N} \cos ^{2} \theta_{f}-\left(1-d_{m a t} \boldsymbol{\delta}_{i j}\right) \sigma_{N T} \sin 2 \theta_{f}+\sigma_{T T} \sin ^{2} \theta_{f} \\
\sigma_{33}=\left(1-d_{m a t} \boldsymbol{\delta}_{i j}\right) \sigma_{N N} \sin ^{2} \theta_{f}+\left(1-d_{m a t} \boldsymbol{\delta}_{i j}\right) \sigma_{N T} \sin 2 \theta_{f}+\sigma_{T T} \cos ^{2} \theta_{f},
\end{gathered}
$$




$$
\begin{gathered}
\sigma_{12}=\left(1-d_{m a t} \boldsymbol{\delta}_{i j}\right) \sigma_{L N} \cos \theta_{f}-\sigma_{L T} \sin \theta_{f} \\
\sigma_{13}=\left(1-d_{m a t} \boldsymbol{\delta}_{i j}\right) \sigma_{L N} \sin \theta_{f}+\sigma_{L T} \cos \theta_{f} \\
\sigma_{23}=\left(\frac{\left(1-d_{m a t} \boldsymbol{\delta}_{i j}\right) \sigma_{N N}-\sigma_{T T}}{2}\right) \sin 2 \theta_{f}+\left(1-d_{m a t} \boldsymbol{\delta}_{i j}\right) \sigma_{N T} \cos 2 \theta_{f}
\end{gathered}
$$

\section{Application in FE simulations}

With the exception of the first sub-heading below, the same section headings and subheadings have been used in this section, as those presented in [2], for facilitating the comparison of results.

\subsection{Constrained single element test}

Two different constrained single element simulations were carried out with identical boundary conditions to those suggested in [1], Fig. 5. The results of the first simulation, shown in Fig. 6a, were obtained using the proper implementation of the damage model in [2] where it is evident that the correct behaviour was captured. In Fig. $6 \mathrm{~b}$ the model was executed with the Poisson ratio degradation deactivated where it is noted that, in this instance, the incorrect behaviour presented in [1], and erroneously attributed to the formulation in [2], is reproduced. This is one, but perhaps not the only, possible explanation for the error in Bogenfield's and Kreikemeier's implementation of Falzon's model. 


\subsection{Minimal example: tensile specimen}

A simple tensile test simulation, under displacement control, was conducted using a mesh density shown in Fig. 7a and boundary conditions given in Fig. $7 \mathrm{~b}$. The element size was $1 \mathrm{~mm} \times 1 \mathrm{~mm} \times$ $1 \mathrm{~mm}$, and 40 C3D8R elements were used.

A comparison of the force versus displacement curves, obtained using the damage model in [2], Fig. $8 \mathrm{a}$, and as presented by Bogenfeld and Kreikemeier's [1], Figs 8b, shows that Bogenfeld and Kreikemeier's claim that the model in [2] leads to 'a permanently oscillating response' is not correct. It is further demonstrated in Fig. 9a that an appropriate crack band is formed using Falzon's damage model [2] and not the distortion reported by Bogenfeld and Kreikemeier [1], reproduced in Fig. 9b.

\subsection{Compression of cubic specimen}

The cubic specimen compression test, described in Bogenfeld and Kreikemeier's paper [1], was replicated in this work using Falzon's damage model [2]. The finite element model is shown in Fig. 10. Damage initiation, at each corner of the specimen, was predicted correctly with the defective version of Falzon's model implemented by Bogenfeld and Kreikemeier in [1]. In such idealised computational specimens, damage is expected to propagate from these edges to form diagonal cracks. This is indeed what is observed in the current work where the results are presented in Fig. 11a. Fig. 11b shows the results obtained by Bogenfeld and Kreikemeier [1].

It is immediately obvious that the current work produces a clear crack path and does not 'lead to rather diffusely damaged elements' as claimed in [1]. Neither do the results in Fig. 11a exhibit 'non-physical 
effects' at the edges. This is, presumably, a reference to the high level of element distortion obtained by Bogenfeld and Kreikemeier [1].

\section{Application on a low velocity impact (LVI) model}

A number of papers by Falzon's research group $[2,3,8,10]$ have reported excellent correlation between experimental impact tests and predictive computational modelling. Moreover, recent developments have further demonstrated the ability of this damage model to accurately predict compression-afterimpact behaviour [3] and assess the crushing response of composite specimens $[4,9,11]$. These studies attest to the robustness and stability of the damage model. It was, therefore, with a considerable degree of incredulity that the authors of this paper viewed the force vs time and force vs displacement curves reported by Bogenfeld and Kreikemeier (Fig 15 in [1]) which showed a surprising degree of instability which has never been observed using the proper implementation of Falzon's damage model.

The results of impact simulation obtained from Bogenfeld and Kreikemeier's work [1] are shown in Fig. 12. The LVI specimen described by Bogenfeld and Kreikemeier [1] was reproduced by the authors and executed using the damage model in [2]. The resulting force vs time and force vs displacement curves are shown in Fig. 13a and 13b, respectively. It is clearly evident that excellent correlation was achieved with no evidence of instability issues.

\section{References}

[1] Bogenfeld R, Kreikemeier J. A tensorial based progressive damage model for fiber reinforced polymers. Compos Struct 2017;168:608-18.

[2] Tan W, Falzon BG, Chiu LNS, Price M. Predicting low velocity impact damage and Compression-After-Impact (CAI) behaviour of composite laminates. Compos Part A Appl Sci Manuf 2015;71:212-26.

[3] Brian Falzon, Wei Tan. Predicting Impact Damage, Residual Strength and Crashworthiness of Composite Structures. SAE Int J Mater Manuf 2016;9:718-28. 
[4] Chiu LNS, Falzon BG, Chen B, Yan W. Validation of a 3D damage model for predicting the response of composite structures under crushing loads. Compos Struct 2016;147:65-73.

[5] Cauvin, Alix; Testaa RB. Damage mechanics: basic variables in continuum theories. Int J Solids Struct 1999;36:747-61.

[6] Chaboche, J.L. Continuum Damage Mehcanics: Part I---General Concepts. J Appl Mech 1988;55:59-64.

[7] Lemaitre J., Chaboche J.L. A. Mechanics of solid materials. Cambridge: Cambridge University Press; 1990.

[8] Faggiani A, Falzon BG. Predicting low-velocity impact damage on a stiffened composite panel. Compos Part A Appl Sci Manuf 2010;41:737-49.

[9] Tan W, Falzon BG. Modelling the crush behaviour of thermoplastic composites. Compos Sci Technol 2016;134:57-71.

[10] Donadon M V., Iannucci L, Falzon B, Hodgkinson JM, de Almeida SFM. A progressive failure model for composite laminates subjected to low velocity impact damage. Comput Struct 2008;86:1232-52.

[11] Chiu LNS, Falzon BG, Ruan D, Xu S, Thomson RS, Chen B, et al. Crush responses of composite cylinder under quasi-static and dynamic loading. Compos Struct 2015;131:90-8.

[12] Chiu LNS, Falzon BG, Boman R, Chen B, Yan W. Finite element modelling of composite structures under crushing load. Compos Struct 2015;131:215-28.

[13] Tan W, Falzon BG. Modelling the nonlinear behaviour and fracture process of AS4/PEKK thermoplastic composite under shear loading. Compos Sci Technol 2016;126:60-77.

[14] Tan W, Falzon BG, Price M, Liu H. The role of material characterisation in the crush modelling of thermoplastic composite structures. Compos Struct 2016;153:914-27.

[15] Puck A, Schürmann H. Failure analysis of FRP laminates by means of physically based phenomenological models. Compos Sci Technol 1998;58:1045-67.

[16] Tan W, Falzon BG, Chiu LNS, Price M. Predicting low velocity impact damage and Compression-After-Impact (CAI) behaviour of composite laminates. Compos Part A Appl Sci Manuf 2015;71:212-26.

[17] Falzon BG, Apruzzese P. Numerical analysis of intralaminar failure mechanisms in composite structures. Part I: FE implementation. Compos Struct 2011;93:1039-46. 
Figures
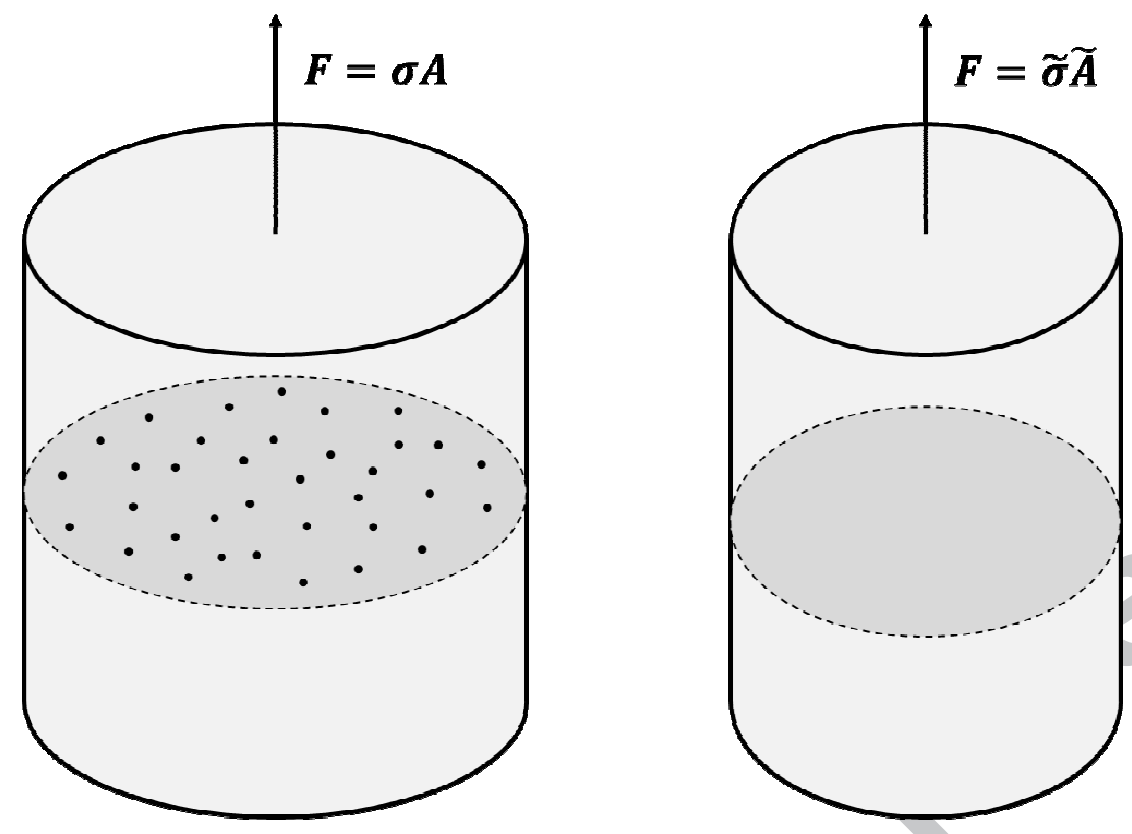

Fig. 1. Micro-cracking (left) which reduces the effective load bearing area from $A$ to $\tilde{A}$.

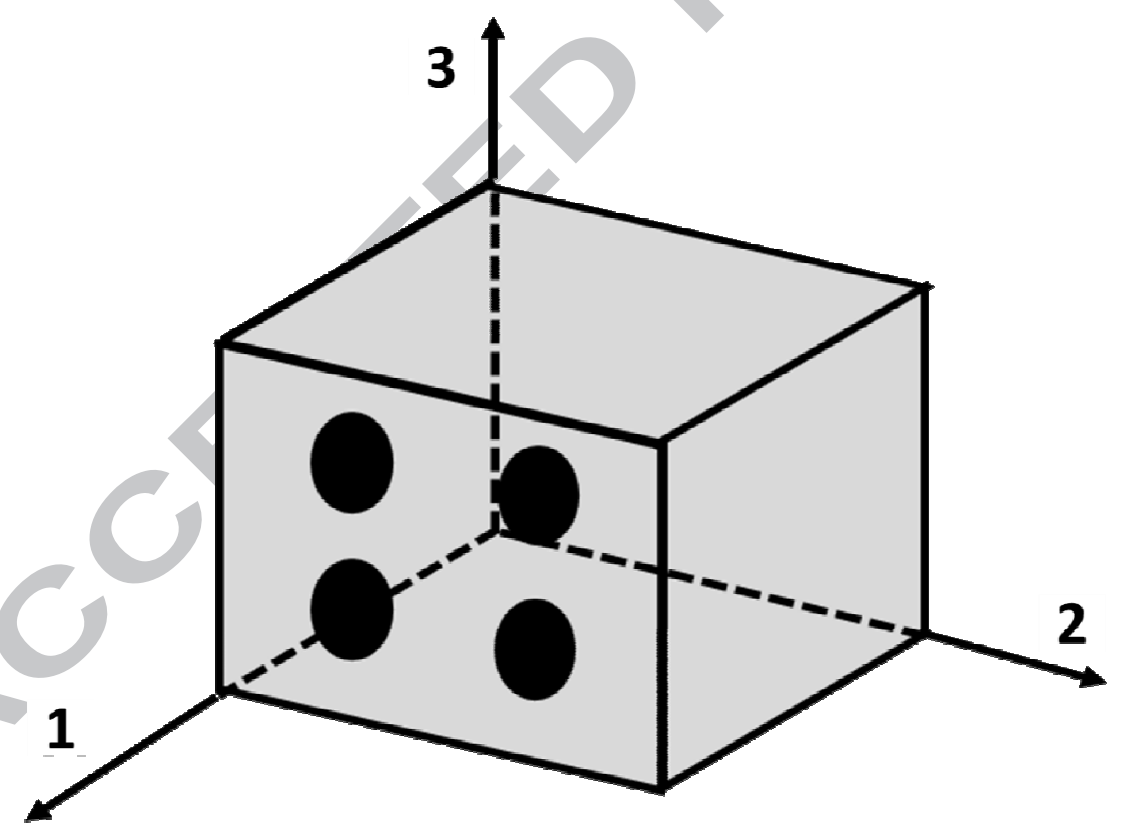

Fig. 2. Representative Volume Element (RVE) of a unidirectional composite ply. 


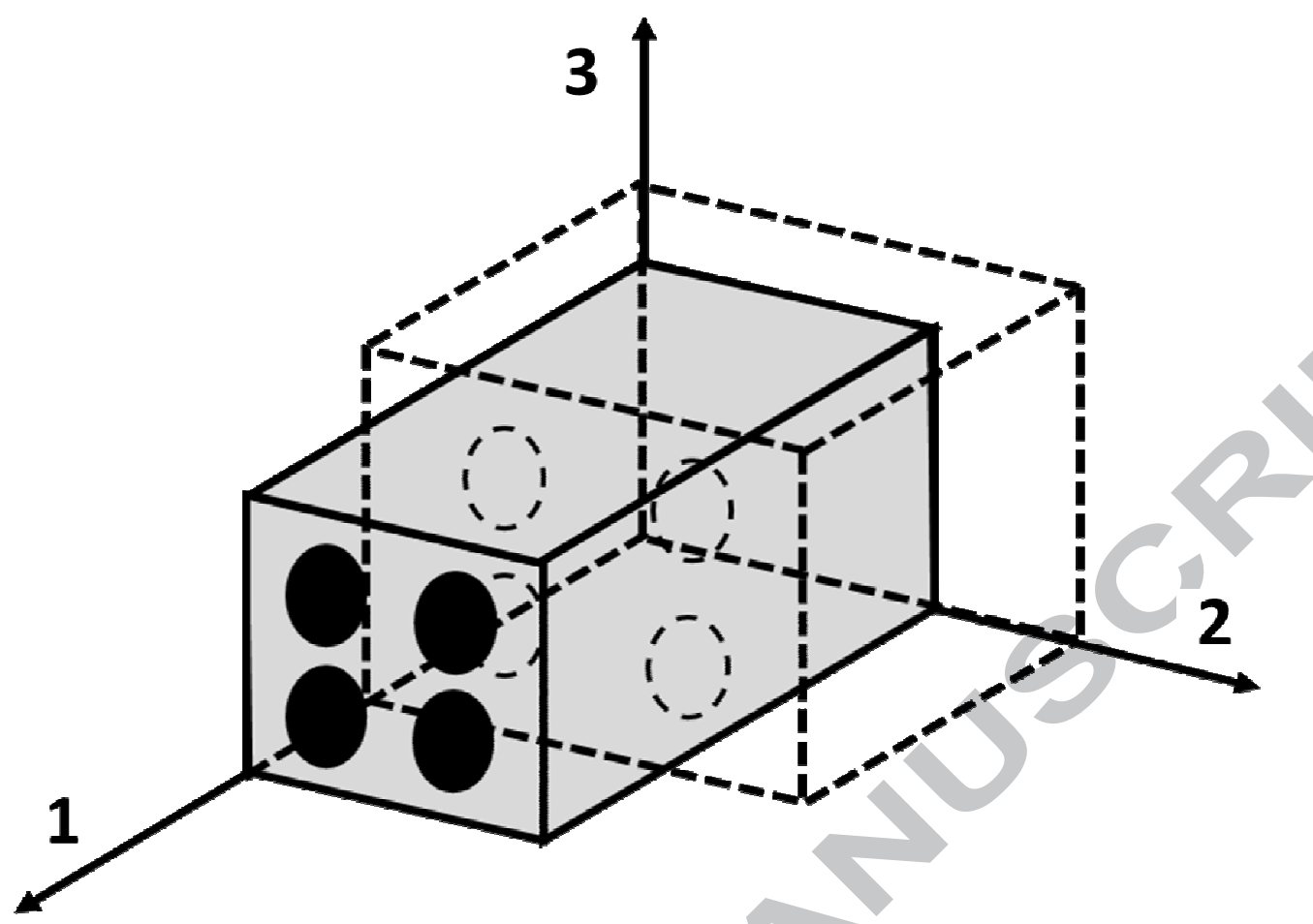

Fig. 3. RVE loaded in the fibre direction.

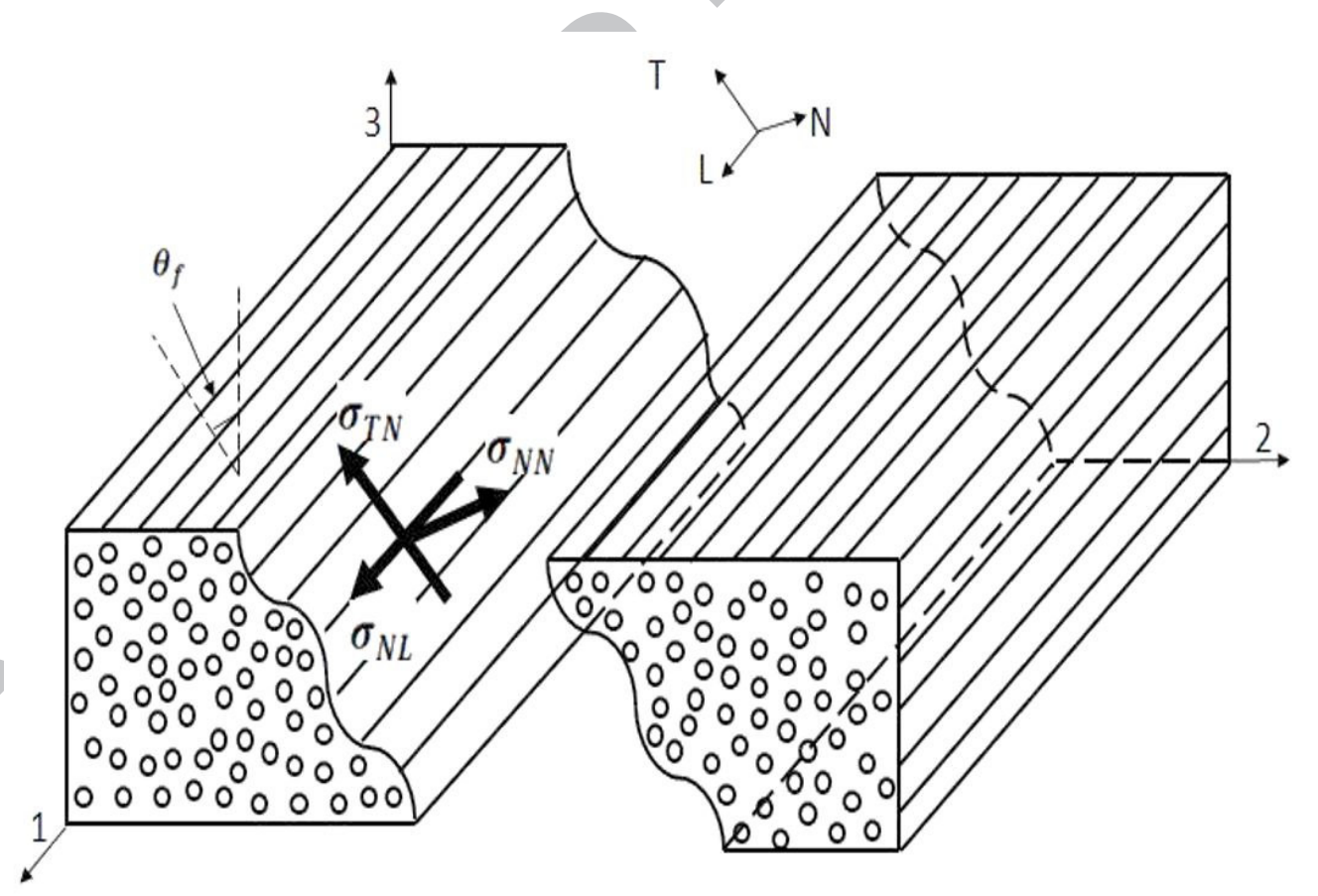

Fig. 4. Fracture plane and corresponding coordinate system. 


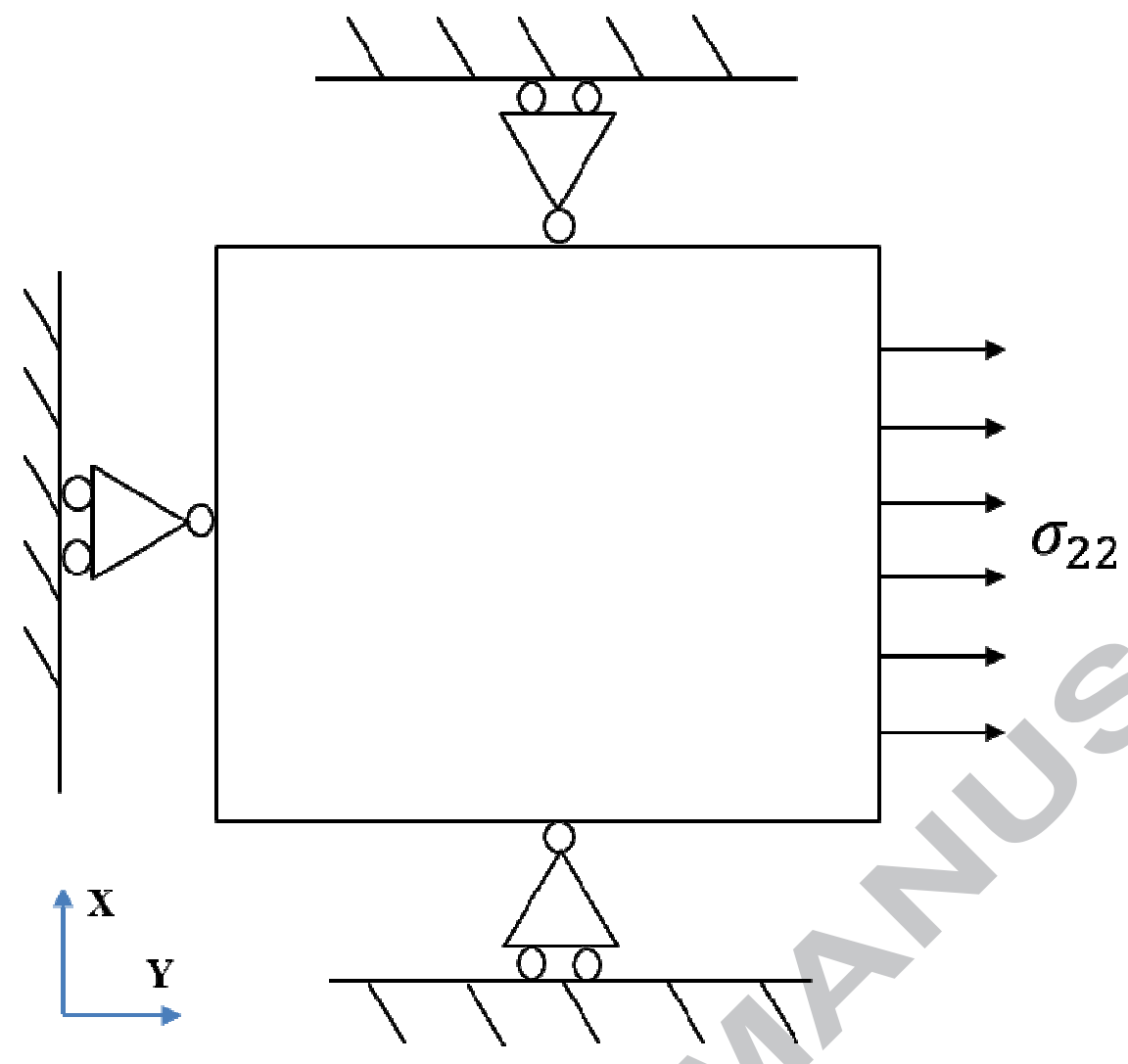

Fig. 5. Boundary condition of single element tensile simulation.

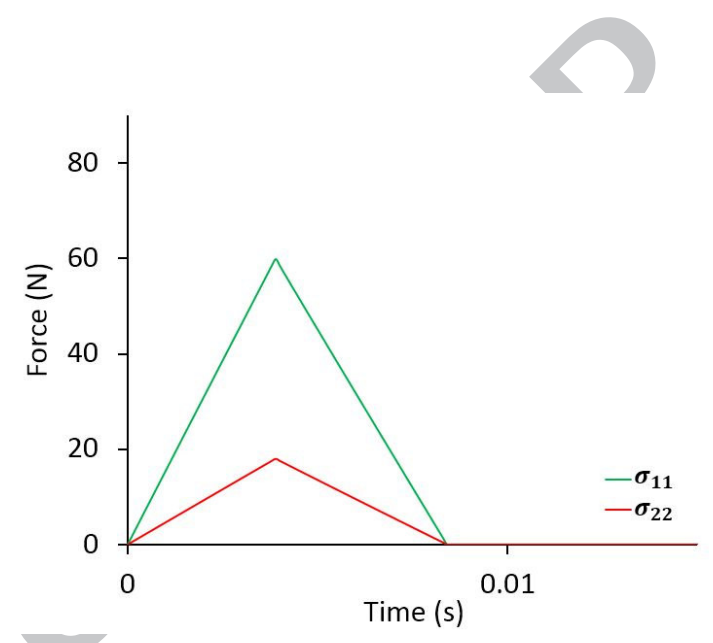

(a)

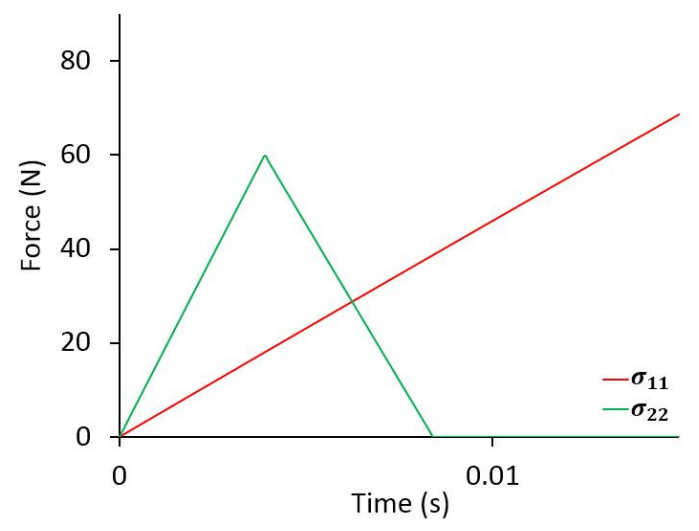

(b)

Fig. 6. (a) Correct results obtained from the damage model reported in [2] (b) results obtained with Poisson ratio degradation deactivated (cf. Fig, 3 in [1]). 


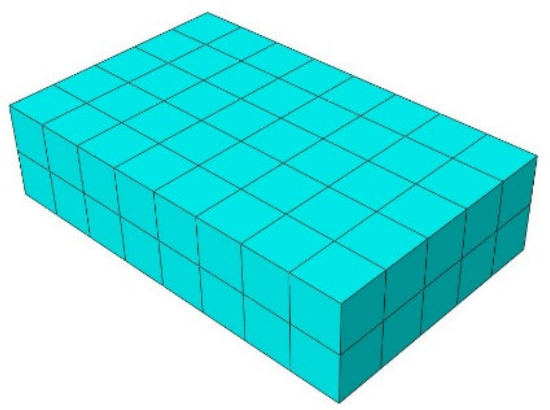

(a)

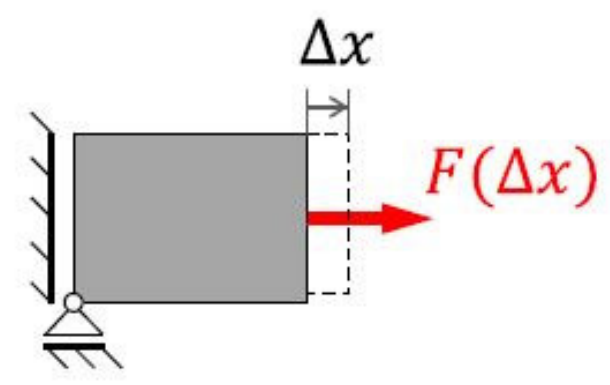

(b)

Fig. 7. (a) FE model for minimal tensile specimen (b) boundary condition of minimal tensile specimen.

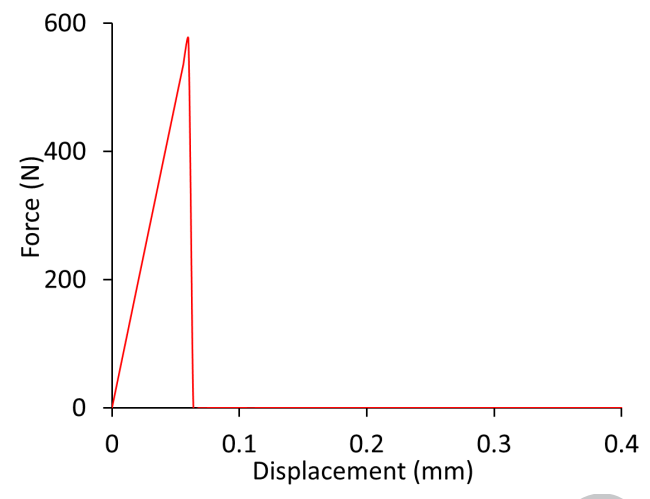

(a)

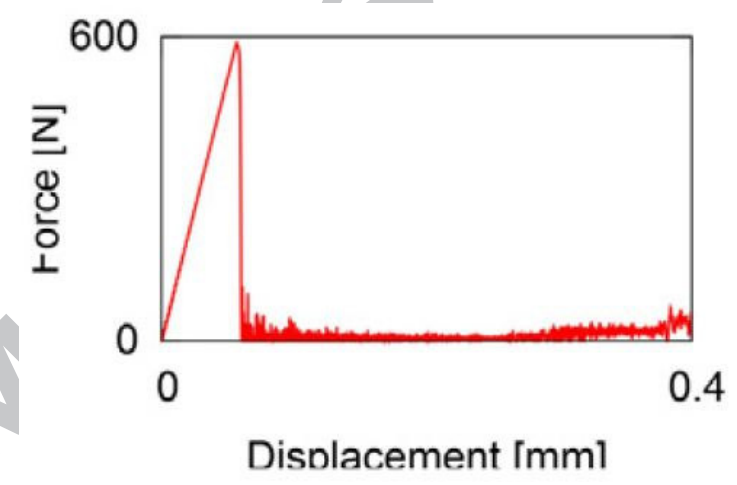

(b)

Fig. 8. Force history curve (a) obtained using the damage model reported in [2] (b) as presented in Bogenfeld and Kreikemeier's paper (Table 1, [1]).

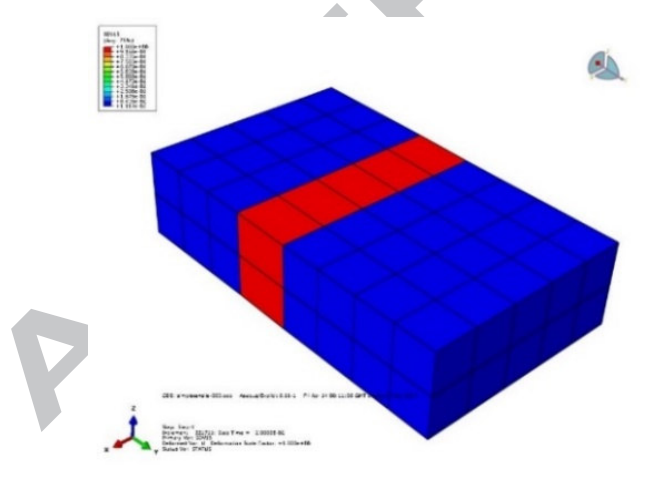

(a)

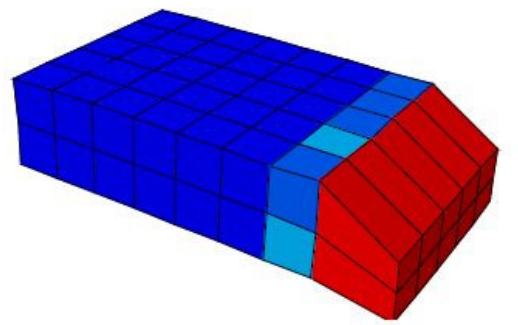

(b)

Fig. 9. Crack band formation (a) obtained using the damage model reported in [2], and (b) as reported by Bogenfeld and Kreikemeier [1]. 


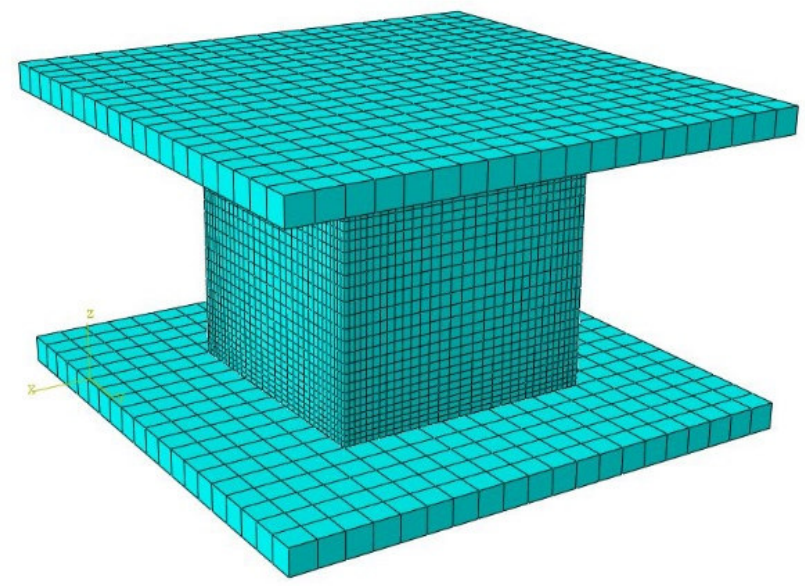

Fig. 10. Finite element model of the cubic compression test simulation.
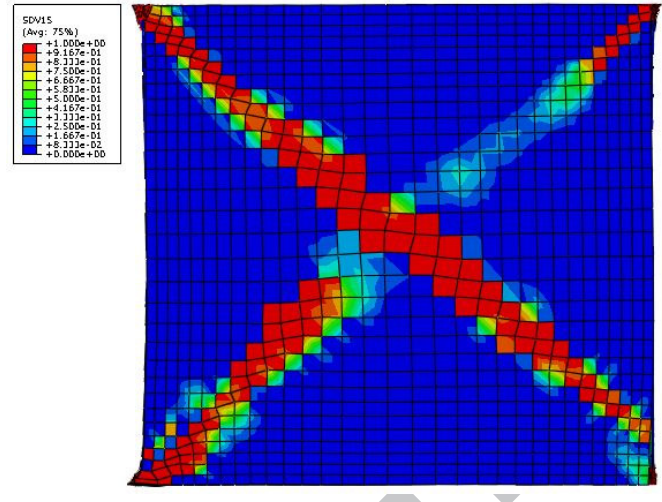

(a)

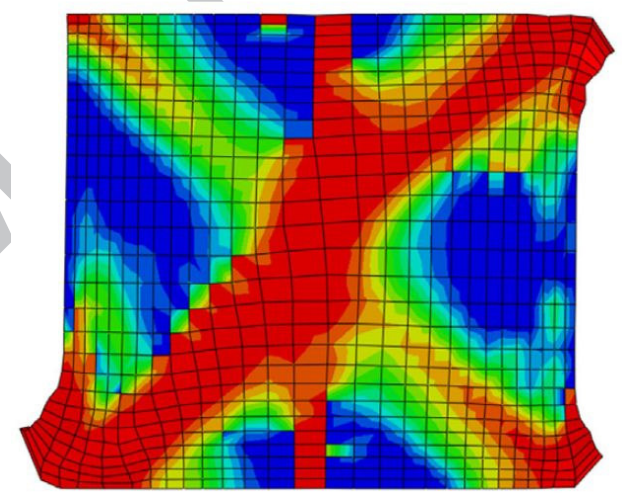

(b)

Fig. 11. Diagonal crack formation in cubic specimen compression test (a) obtained using the damage model reported in [2], and (b) as reported by Bogenfeld and Kreikemeier [1]. 


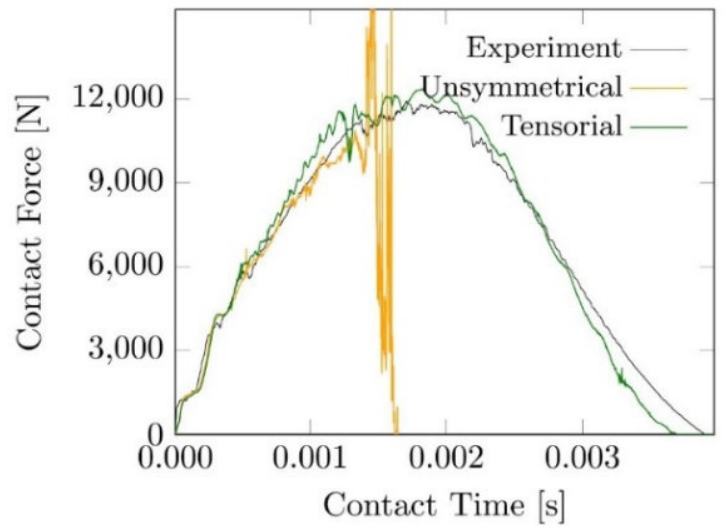

(a)

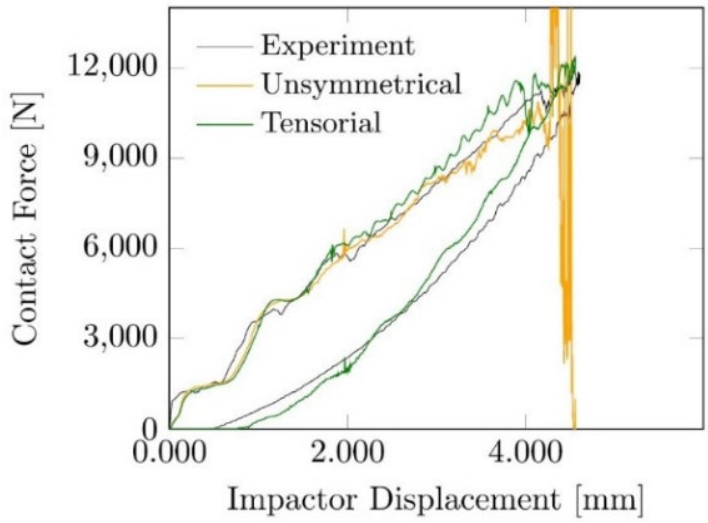

(b)

Fig. 12. (a) Force versus time and (b) force versus displacement curves presented in Bogenfeld and Kreikemeier's work [1].

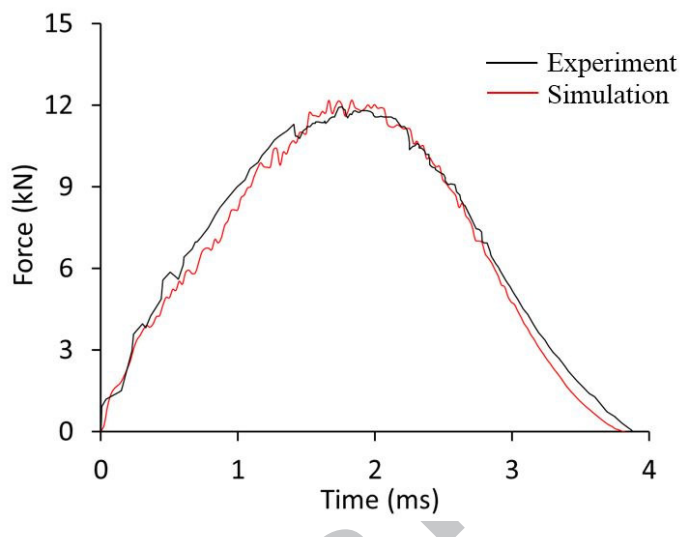

(a)

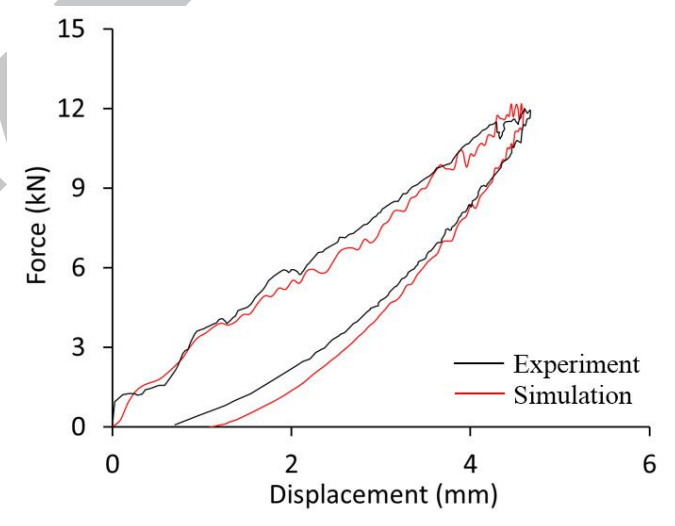

(b)

Fig. 13. (a) Force versus time and (b) force versus displacement curves obtained using the damage model reported in [2]. 